Bull.Fac, Agric.,Cairo Univ.,62: 14-22 (2011).

\title{
FAMILY SUPPORT FOR RURAL AGED: A CASE STUDY OF THE LOCAL UNIT OF QUNAIESET ALSARADOSY, KAFR EL-SHAIKH GOVERNORATE
}

(Received: 26. 9. 2010)

\author{
By \\ M. H. Nawar, S. M. Elzoughby, M. S. M. Kamal and H. S. Abdelaziz \\ Department of Rural Sociology and Agricultural Extension, Faculty of Agriculture, \\ Cairo University, Giza, Egypt.
}

\begin{abstract}
Recently, according to the theory of demographic transition, there is a trend towards increasing numbers and proportions of elder people. In many developing countries aged persons receive a good care from their families, and remain part of the extended family. This study aimed to: 1- Identify the economic, health, social and psychological support provided by the families to their elders. 2- Identify the relationships between the different types of support provided by the families to their elders, and the aged sex. Field data were collected using a pretested questionnaire from a random sample of 150 aged persons in one of the rural local units (Qunaieset Alsaradosy) in Kafr El-Shaikh Governorate during the summer of 2008.

The study reached the following results:

All respondents received health support from their families, there were no significant differences between males and females in health support categories, the proportion of males who were receiving strong health support was greater than the proportion of females in the same category. All respondents received economic support from their families, females received more economic support from their families than males, and there were no significant differences between males and females in economic support categories. All respondents received psychosocial support from their families, the proportion of males who were receiving strong psychosocial support was greater than the proportion of females in the same category, and there were no significant differences between males and females in psychosocial support categories. For the overall support of the elders from their families, the proportion of females in both low and medium support categories was higher than those of males in the same categories. The proportion of males who were receiving high support was higher than that of females in the same category, and there were no significant differences between males and females in overall support categories.
\end{abstract}

Key words: family support, Qunaieset Alsaradosy, rural aged.

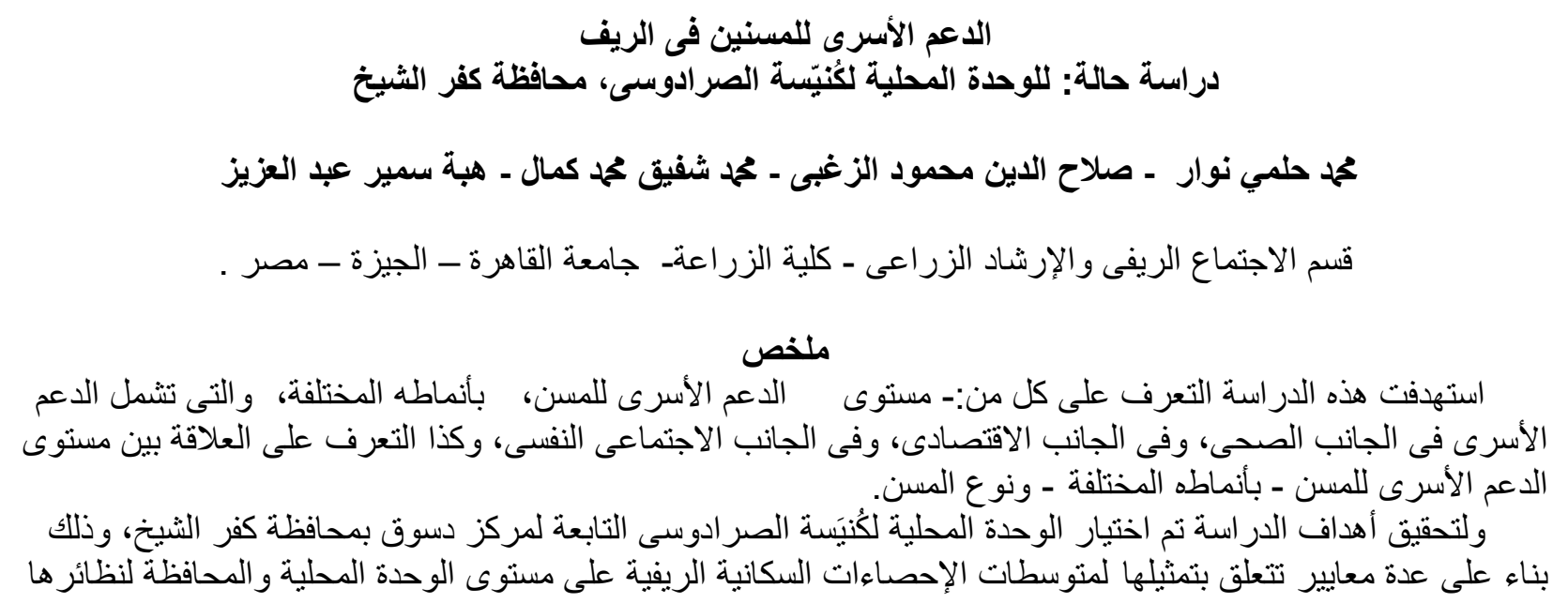


على مستوى الجمهورية.

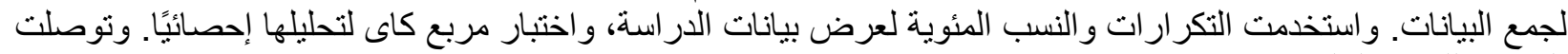

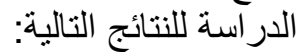

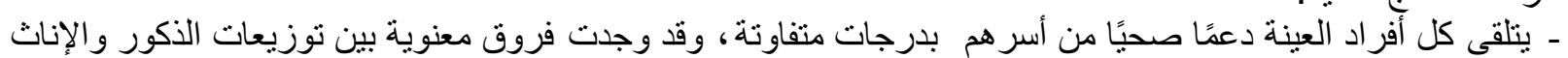

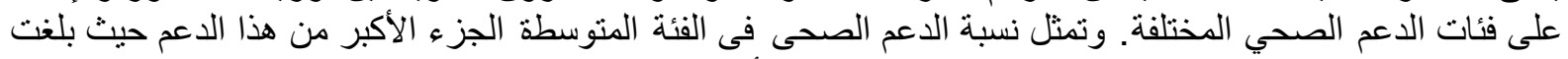

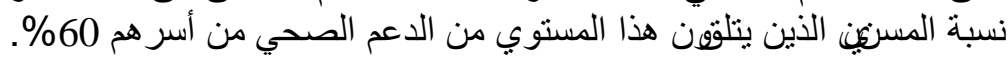

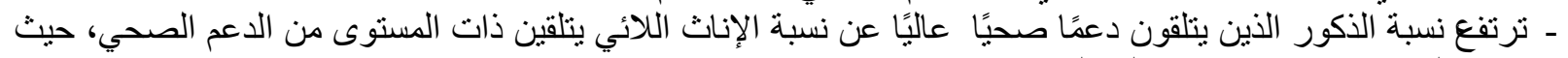

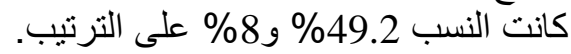

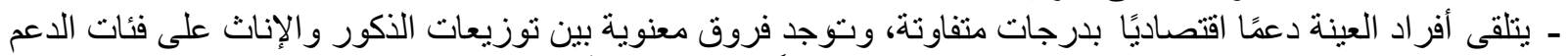

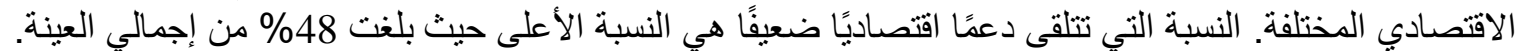

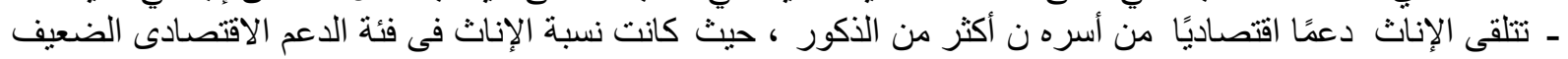

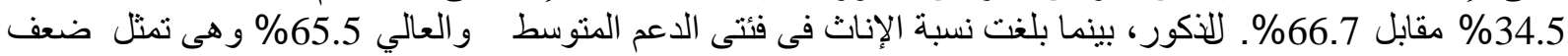

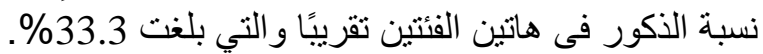

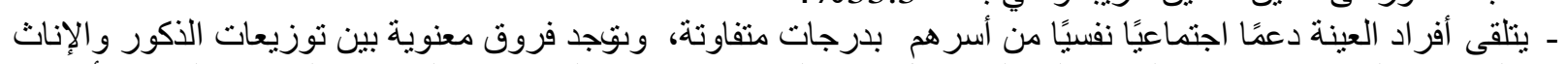

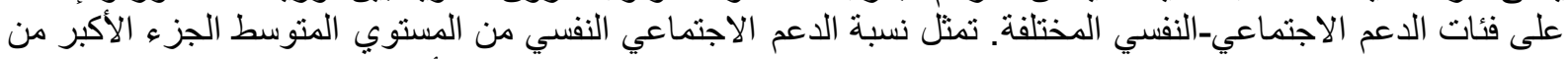

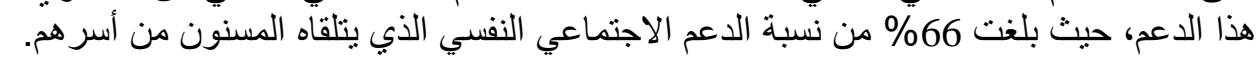

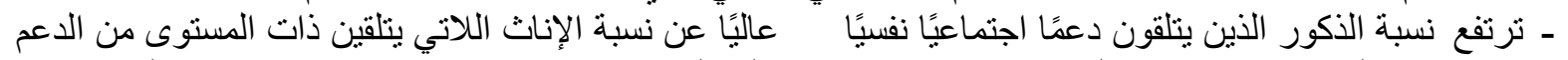

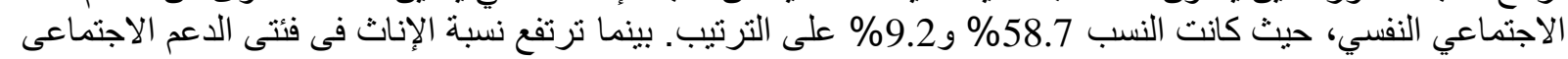

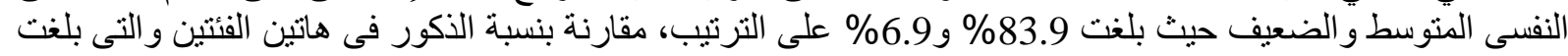

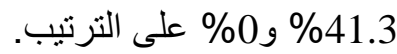

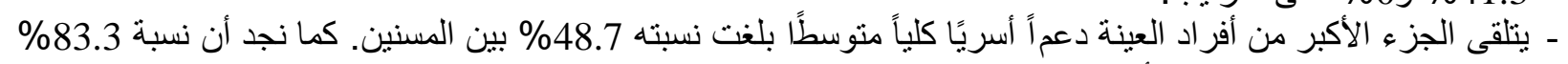

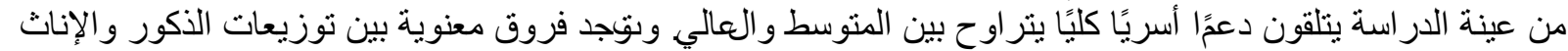

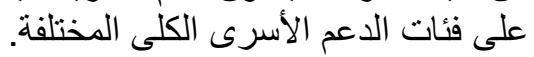

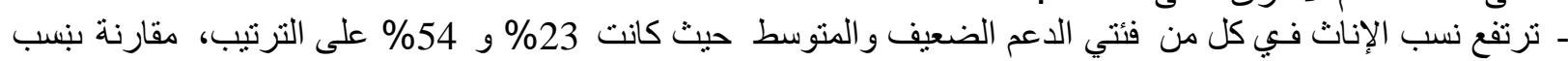

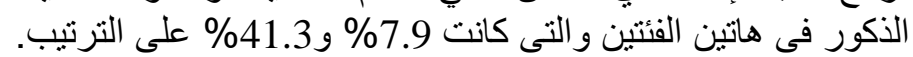

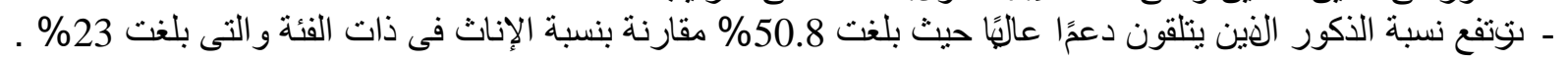

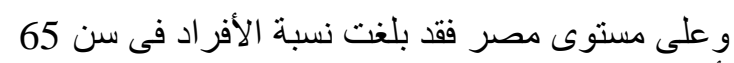

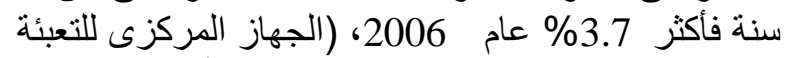

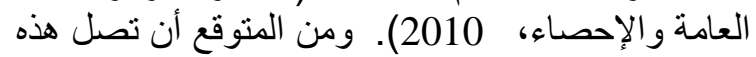
United Nations, ) النسبة إلى الإحنى 19.3\% عام 2050 (2007

كما نلاحظ زيادة نسبة المسنين فى الريف عنها في إنى

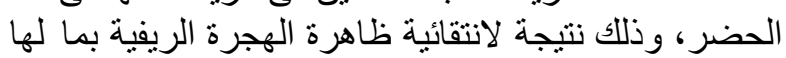

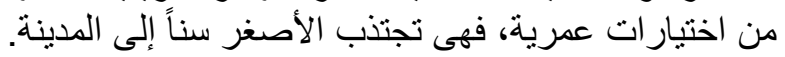

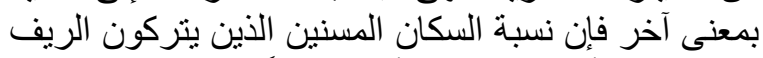

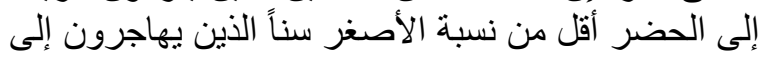

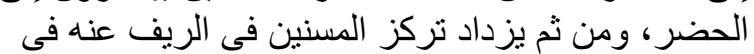

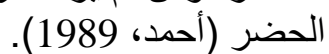

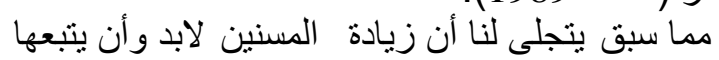

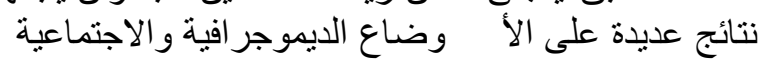

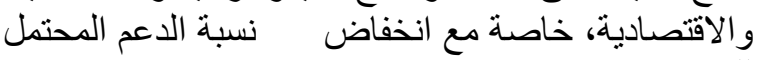
- Potential Support Ratio for Elders - للمسنين الأحنين و الذى يعبر عن عدد السكان فى سن العمل (15 - 64 سنة)

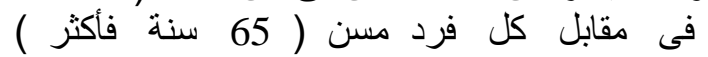
.(United Nations, 1999) تحدث زيادة فى عبء إعالة المسنين، تتمثل فى زيادة

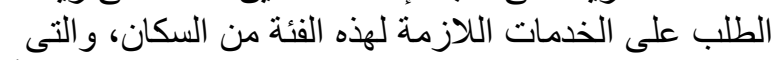
عادة ما يكون لها طابع خاص، سواء فلى الر عاية الصحية أو الو

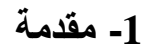

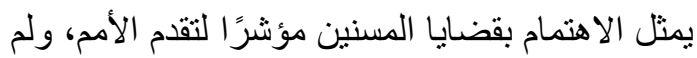

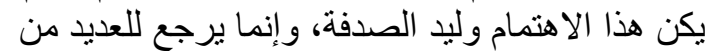

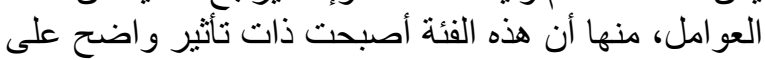

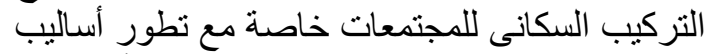

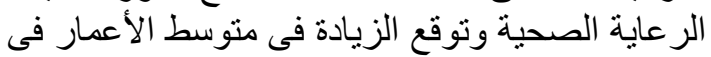
مختلف دول العالم بدرجات مختلفة الزية

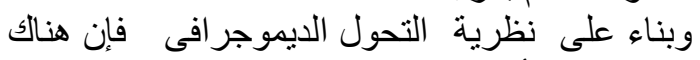

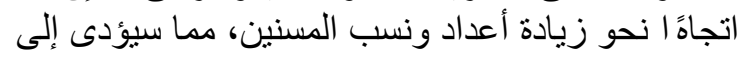

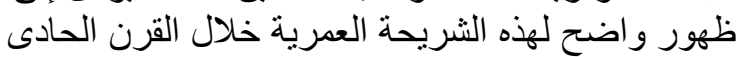

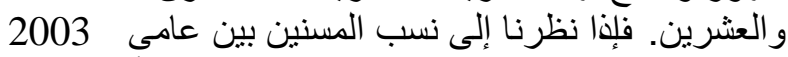

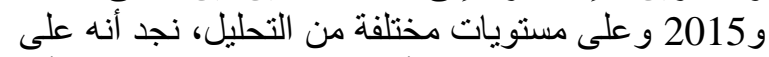
مستوى العالم بلغت نسبة الأفر اد فى سن سن 65 سنة فأكثر

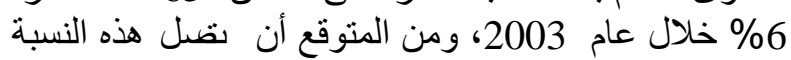

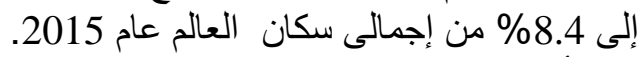

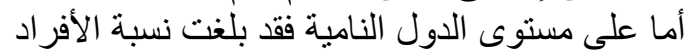

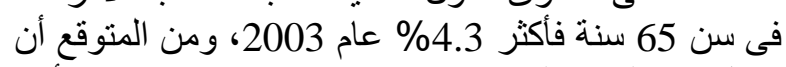

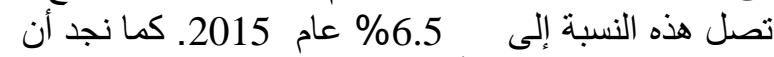
المسريني يزيدون بمعدل أسر على في المناطق النامية، و هذا مما

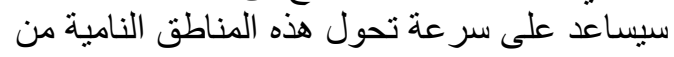

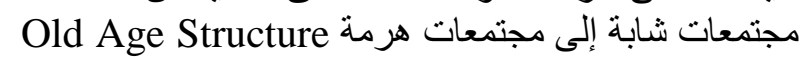
.(United Nations, 1999) 
كما أن تفكلك وحدة الأسرة الممتدة والاتجاه نحو الأسرة

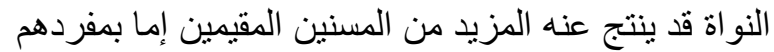

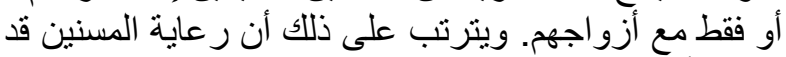

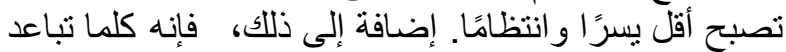

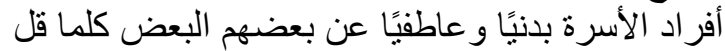

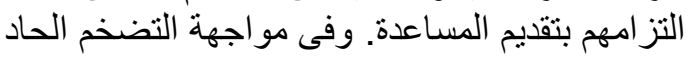

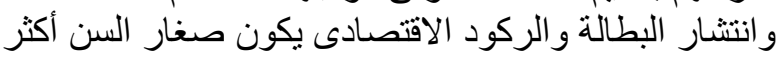

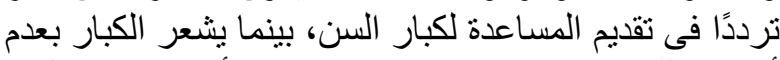
أحقيتهم للمساعدة ويصبحون فى حيرة من أمر هم عند طلبهار البها.

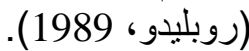
وقد كان للتعقد المجتمعى و التحول الصناعى أثر كبير فى التى

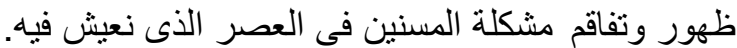

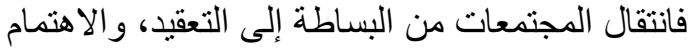

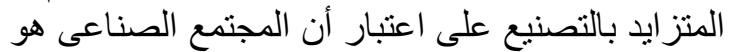

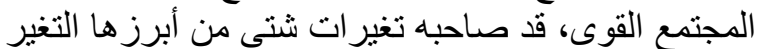

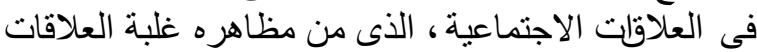

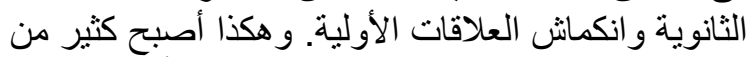

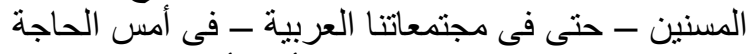

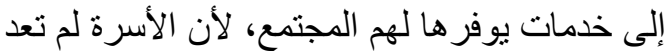

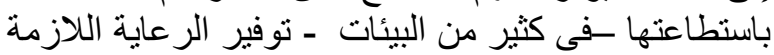

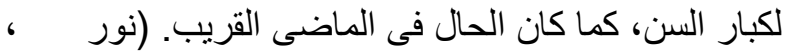
1984

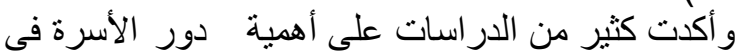

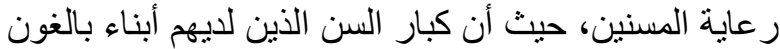

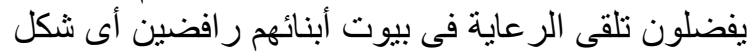

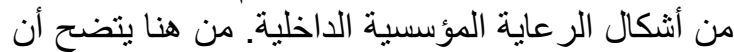

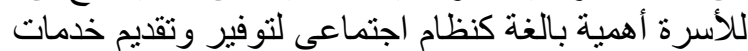

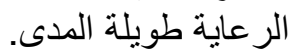

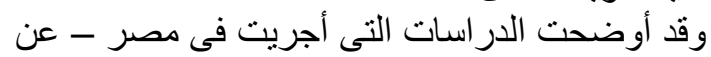

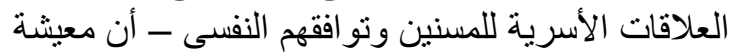

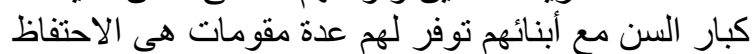

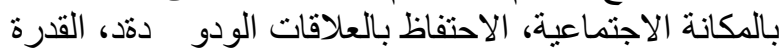
على مساعدة الآخرين (عوض، لاعنة 2001).

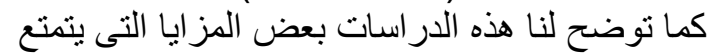

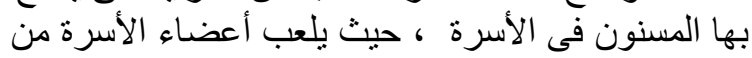

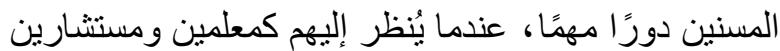

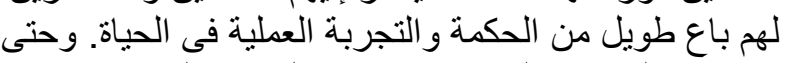

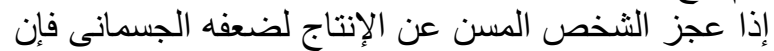
قيمته داخل الأسرة لا تهنز حيث بنظر إليه دائمًا كمثل أعلى الفي وفى إطار ما تقدم نجد أن الرعاية الأسرية توفر للمسن وفن والإنس يحتذى به.

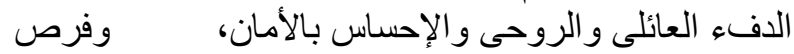

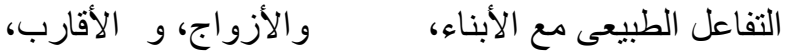

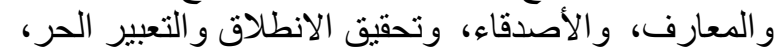

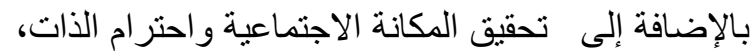

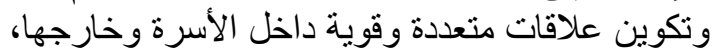

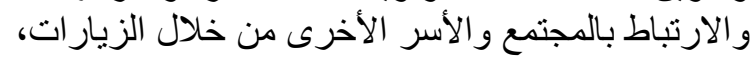

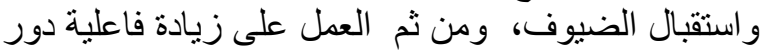

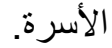

الإسكان أو الترفيه أو تعليم الكبار أو الغذاء وما شابه

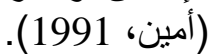

ومن المتوقع أن تزداد حدة هذه المشكلة فى البلدان

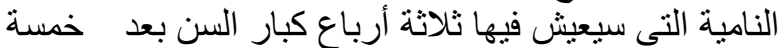

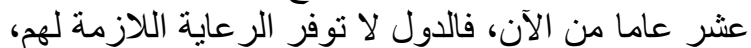

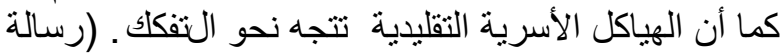

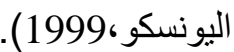

أما في الدول النامية - وبوجه خاص في أفريقيا - فإن

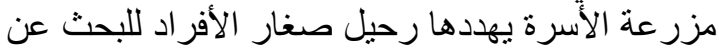

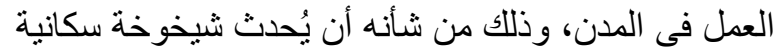

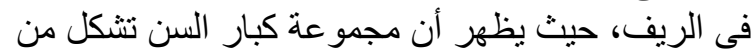

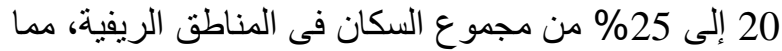

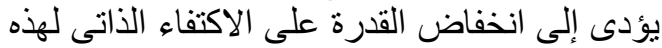

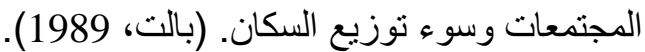

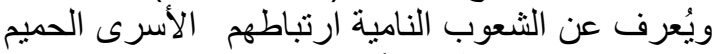

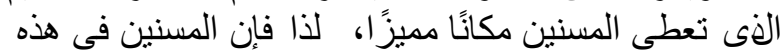

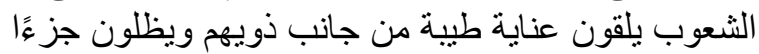

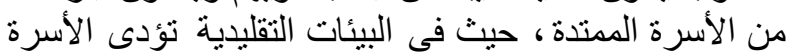

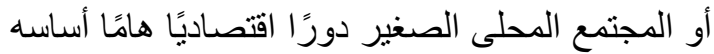

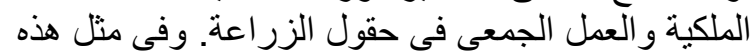

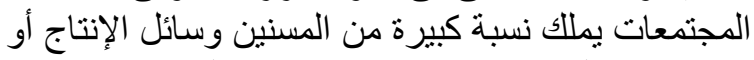

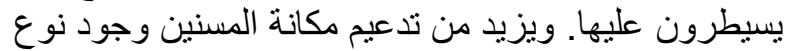

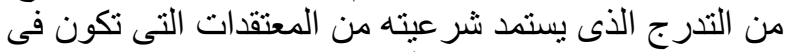

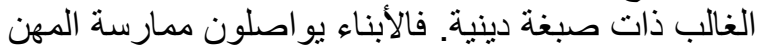

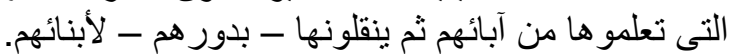

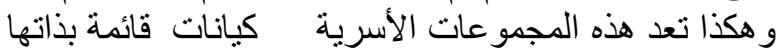

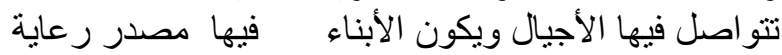

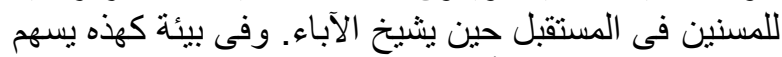
المسنون فى صيانة الأسرة ور عايتها.

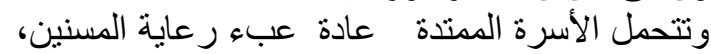

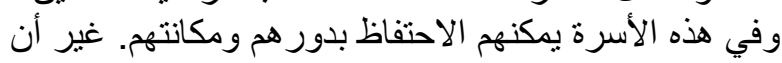

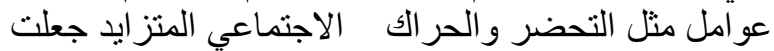

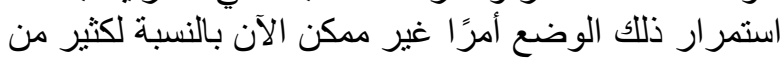

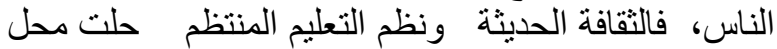

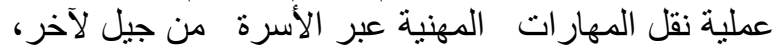

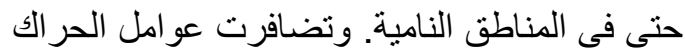

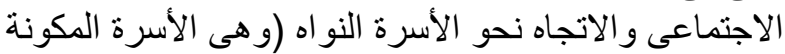

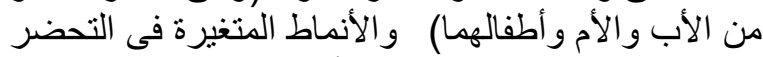

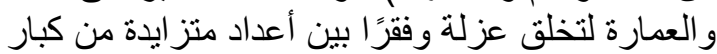

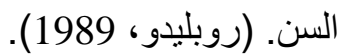

\section{2- 2- 2 مشكلة الدراسة}

تمثل التغير ات الاقتصادية و الاجتماعية فى الدول النية النامية

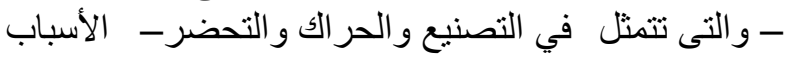

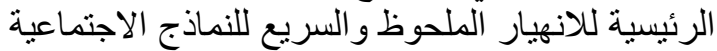

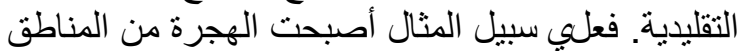

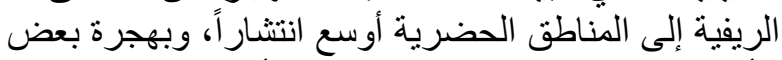
الأفر اد إلى المناطق الحضرية تصنبح الأسرة منفصلة بدنئًا مما ينتج عنه تفتيت وحدات الأسرة الميتدة. الأسترة 
- توجد فروق معنوية بين توزيعات الذكور والإناث على الألى الدئ فئات الدعم الاجتماعى النفسى المختلفئة

- توجد فروق معنوية بين توزيعات الاتئ الذكور و الإناث على الإنى فئات الدعم الكلى المختلفة.

\section{3- الخطة البحثية

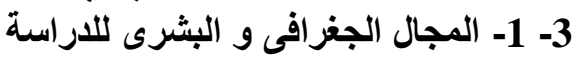

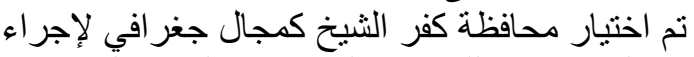

الدر اسة الميدانية، وذلك بناء على على بيانات التعداد التعام

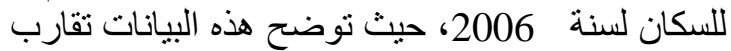

متوسطات الإحصاءات السكانية الريفية على مستوى

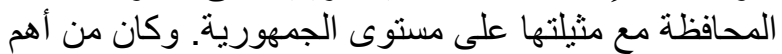
هذه الإحصاءات التى تخص در استنا الحالية، نسبة المسنين

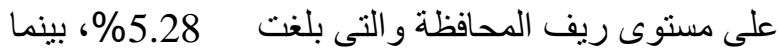
كانت 5.6\% على مستوى ريف الجمهورية. كذلك متوسط

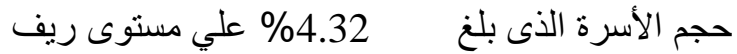

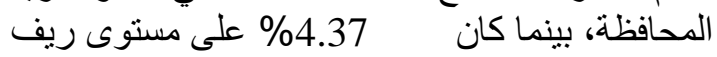

الجمهورية. (الجهاز المركزى للتعبئة العامة و الإحصاء،

كما يوضح نقرير التنمية البشرية الخاص بمصر لسنة

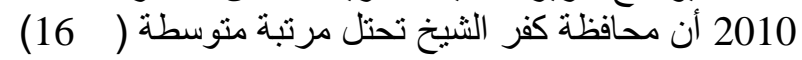

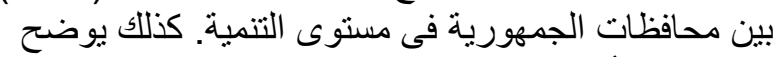

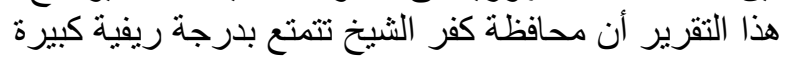

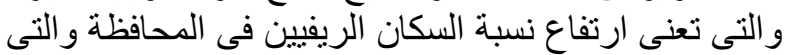

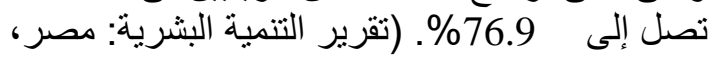

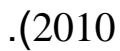

ومن خلال البيانات الخاصة بمحافظة كفر الثيخ الثيخ

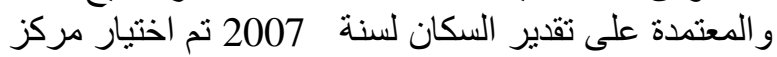

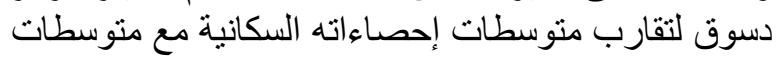
إحصاءات المحافظة فى كل من نسبة المسنين الريفيين،

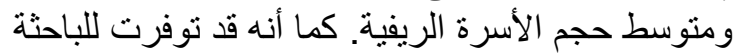

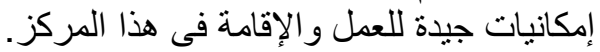
1-1-3 - منطقة الاراسة

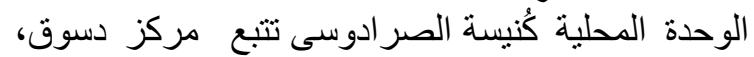

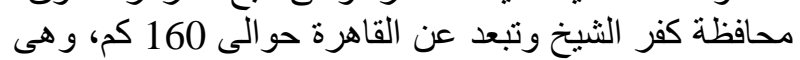

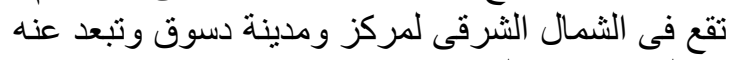

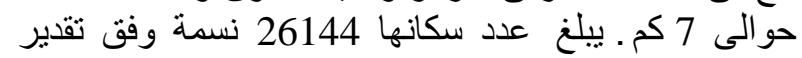

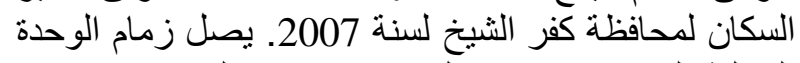

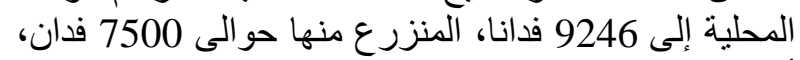

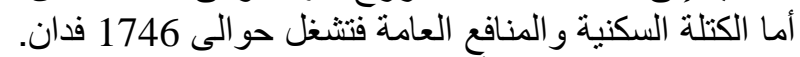

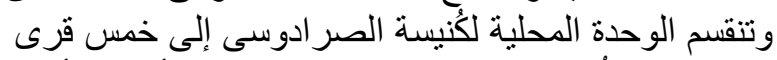

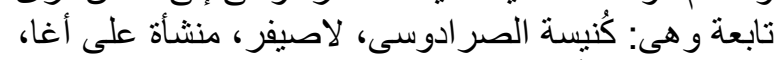

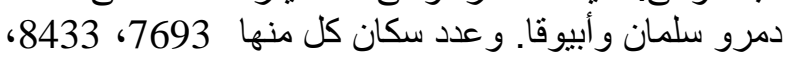

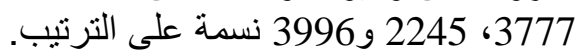
2-1-3- - 2-3 المجال البشرى

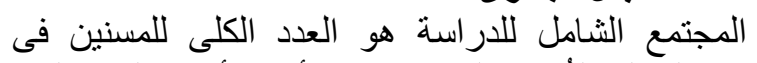

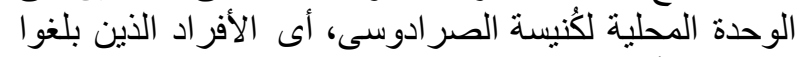

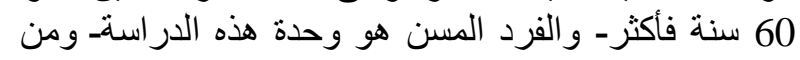

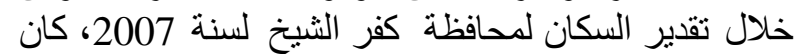
عدد المسنين فى الوحدة المحلية 1266 مسنًا، وهو العنة لعدد
وقد أدرك الأطباء أهية الرعاية المنزلية حيث يوجه إنها

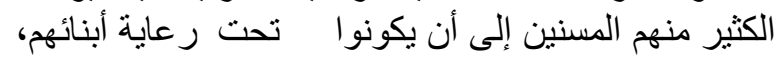

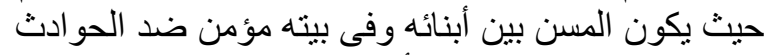

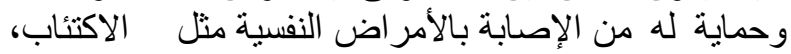
الأرق، الخوف، الحزن. (عبد الإصنة بالأطيف، 1998).

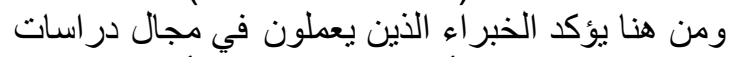

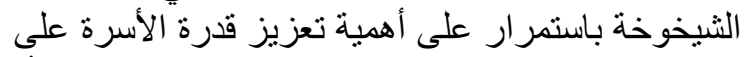

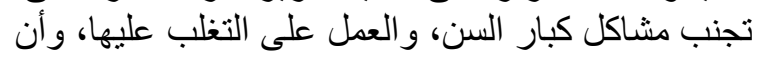

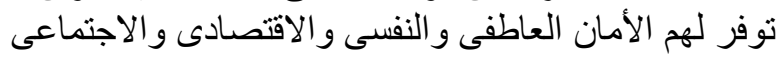

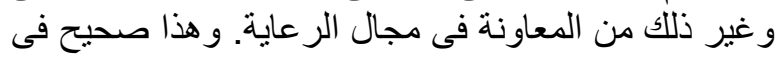

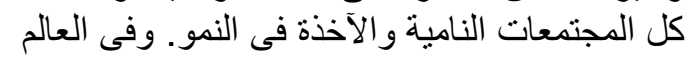

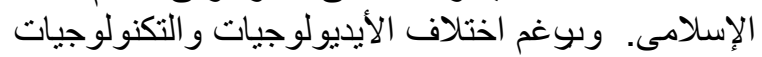

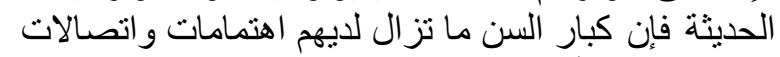

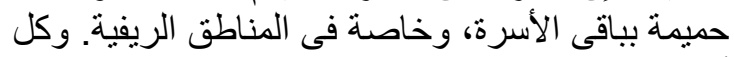

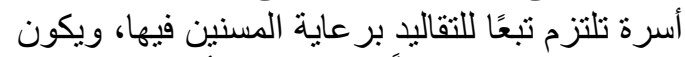

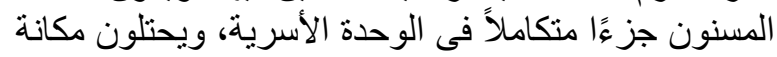

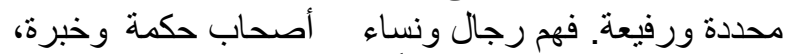

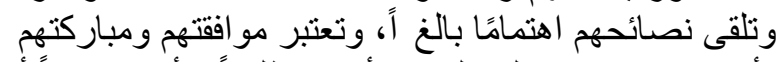

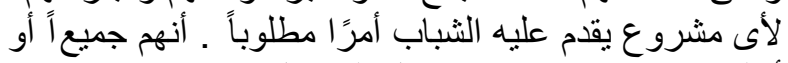

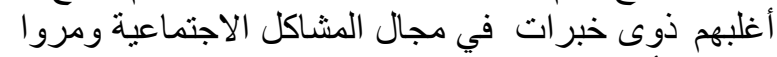

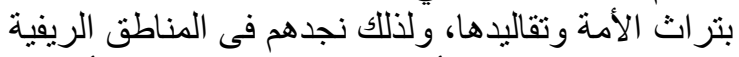

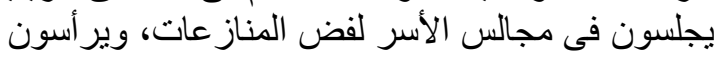

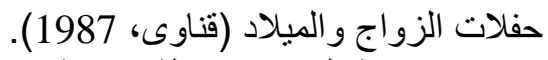

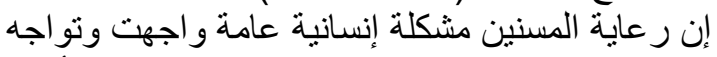

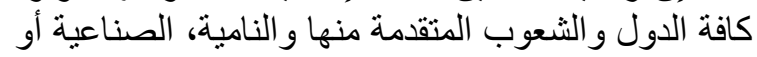

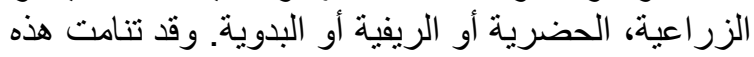

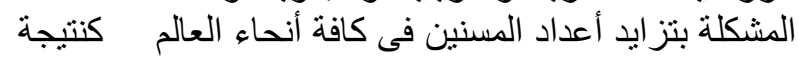

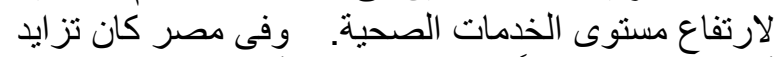

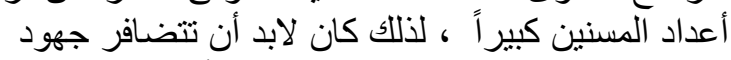

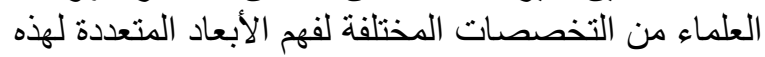

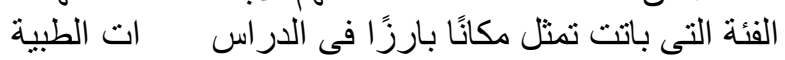

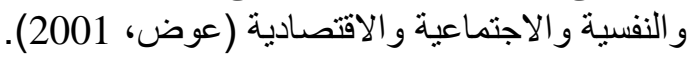

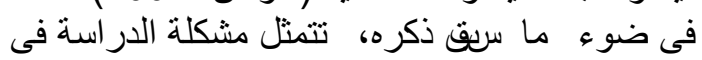

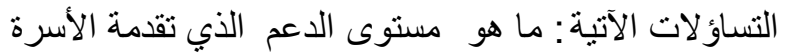

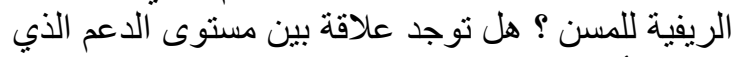
تقدمه الأسرة للمسن ونون المن وجن المسن؟

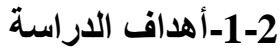
بناء على ما سبق تهدف هذه الدار الدة الدة إلى:

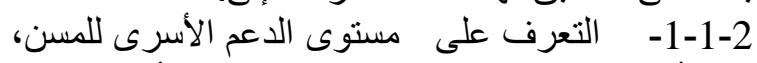

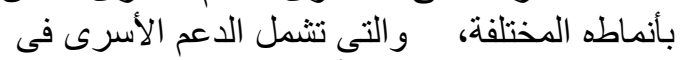

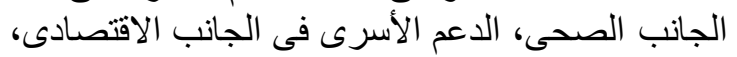

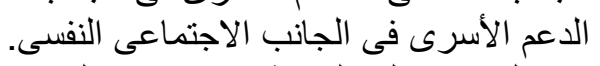

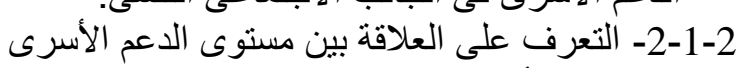

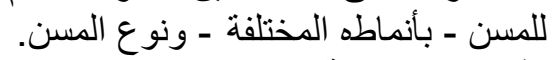

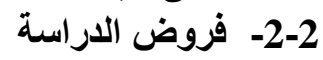
- توجد فروق معنوية بين توزيعات الذكور و الإناث على الإنى

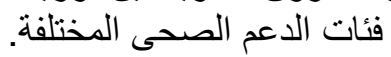

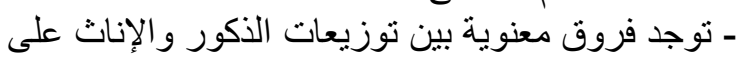
فئات الدعم الاقتصادى المختلفة. 
الصحية للمسن، و التى تشمل الر عاية الصحية و العلاجية والغذائية . وبذللك يعد هذا المتغير متغيرًا مركبًا

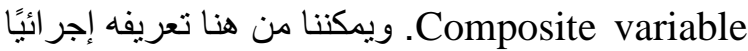
من خلال ثلاثة متغير ات فرعية هي: 1-5-3 - د دعم الأسرة للمسن من الناحية الاقتصادية

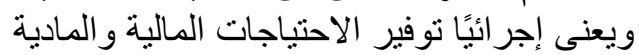

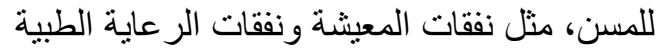

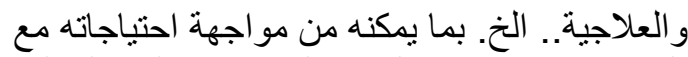
التغيرات الاقتصادية الحادثة له في هذه المئه المرحلة العمرية،

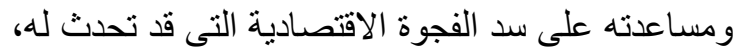

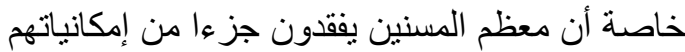
المالية، نتيجة لضعف حالتهم الصحية، و عدم المقدرة على الصى

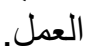

2-5-3 - دعم الأسرة للمسن من الناحية الاجتماعية

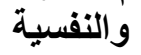

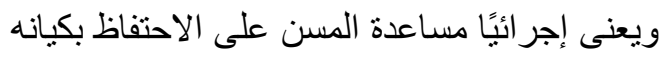

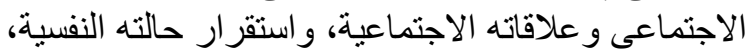

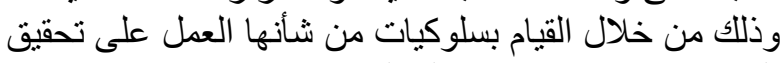

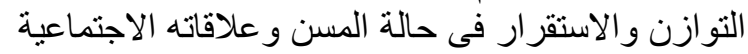

داخل الأسرة وخارجها، وتوفير درجة دالنة من الاستقرار

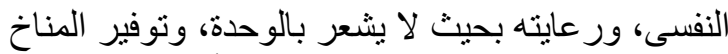

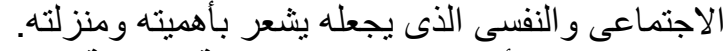

3-5-3 - دعم الأسرة للمسن من الناحية الصحية الأنية

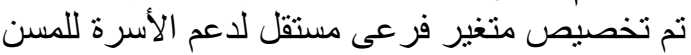

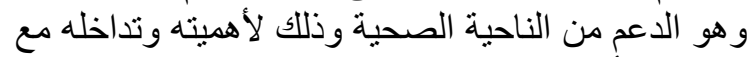
غيره من أنثكال الدعم المختلفة كالدعم الاقتصادى الأني

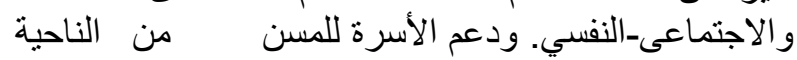

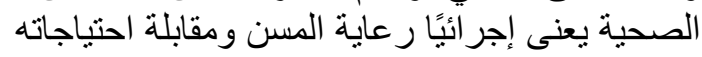

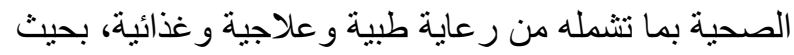

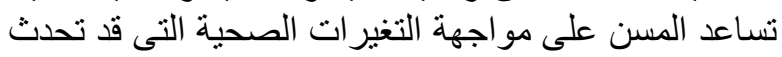
له فى هذه المرحلة العمرية.

\section{6-3-3- وصف عينة الدراسة} 1-6-3 - النوع

أظهرت النتائج الخاصة بعينة الدراسة أن نسبة الذكور

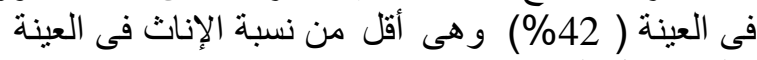
و التى تصل إلى (58\%) (58). 2-6-3 - 2-3 السن

تلوز عاع عينة الدر اسة على ثلاث فئات عمرية، بلغت نسبة

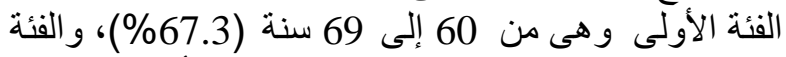

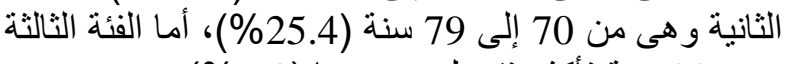
وهى 80 سنة فأكثر فقد بلغت نسبتها (7.3\%). 3-6-3 - الحالة الزواجية

أظهرت نتائج الدراسة أن أفراد العينة ينحصرون في في الزئة

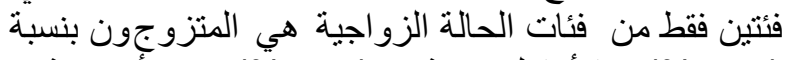

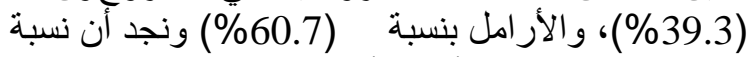

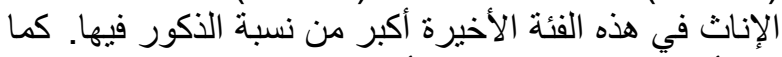

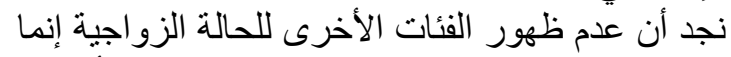

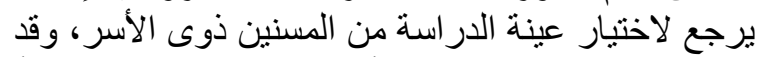
تم تحديد المفهوم الإجر ائى للأسرة في در استنا هذه على الأنى أنها

$$
\text { الذى يمثل الحجم الكلى لمجتمع الدراسة. }
$$

2-3 طريقة اختيار العينة العلية

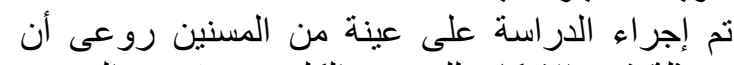

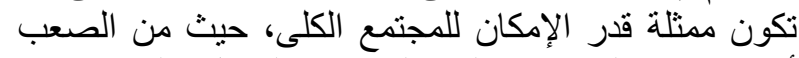

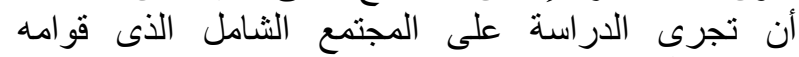

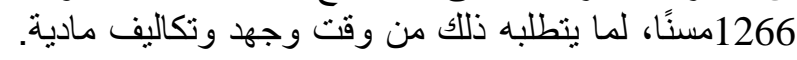
وقد تمت الاستعانة بالمعادلة الإحصائية التالية فى تحديد

$$
\begin{aligned}
& \text { حجم العينة: } \quad n=\frac{N}{(N-1) B^{2}+1} \\
& \text { = } \\
& \text { = = حجم المجتمع الثنامل. = }
\end{aligned}
$$

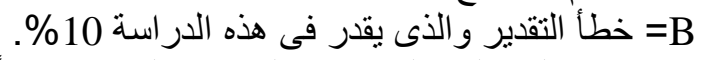

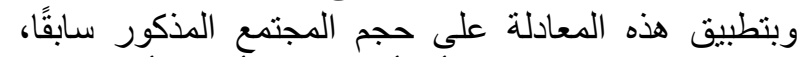
كانت النتيجة هي هذه 92.74، أب أن الحجم الأدنى الأمثل للعينة

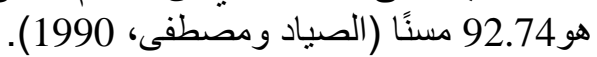

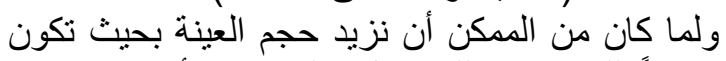

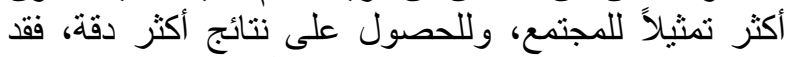

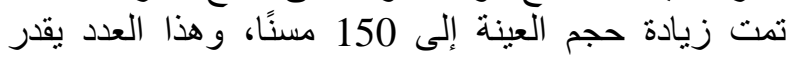

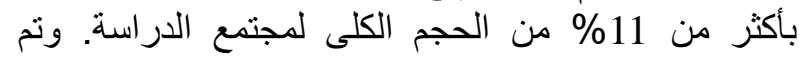

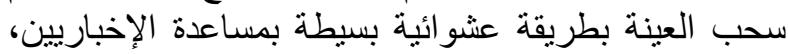

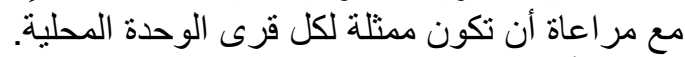
3-3 - أدوات جمع البيانات

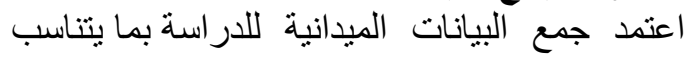

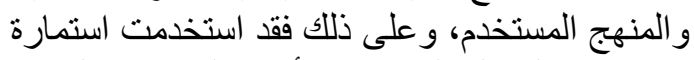

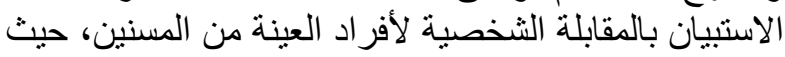

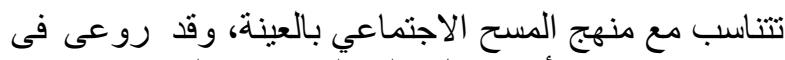

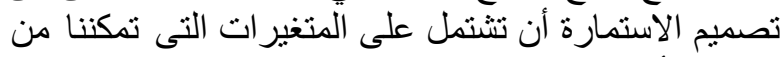
تحقيق الأهداف البحثية. 4-3-3 أدوات التحليل الإحصائي استخدمت أدوات للتحليل الإحصانيل الإحصائي نتلاءم مع طبيعة متغيرات الدر اسة، وكانت كالآتي:

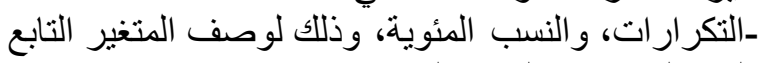
الكلى و المتغير ات التابعة الفر عية.

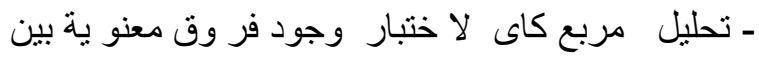

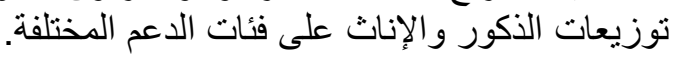

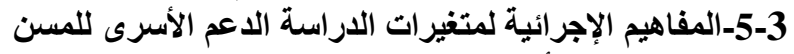

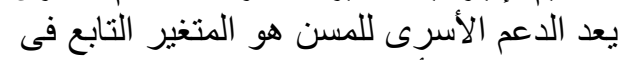

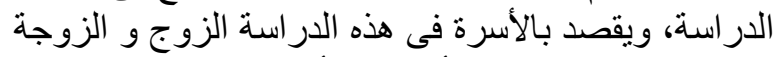

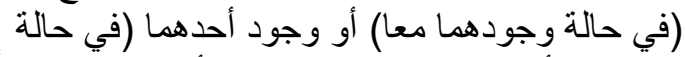
الانفصال أو وفاة الطرف الآخر ) و الأبناء ذكورًا و وإناتًا

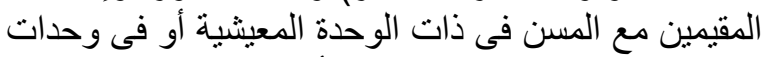

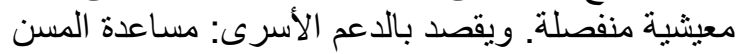

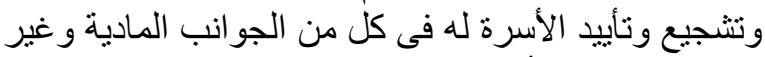

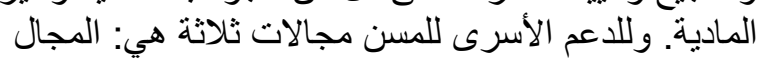

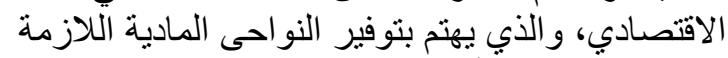

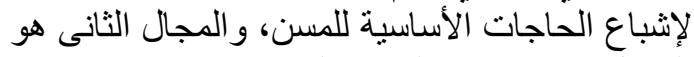

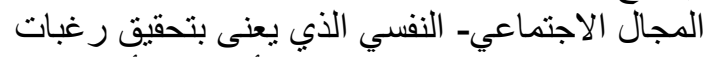

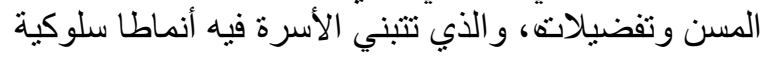

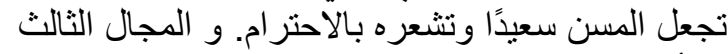

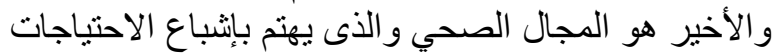




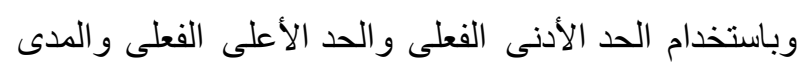

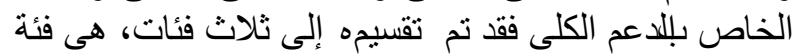

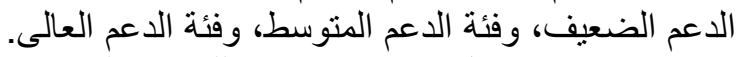

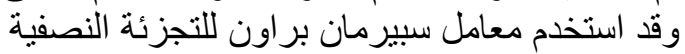
Spearman-Brown split half coefficient

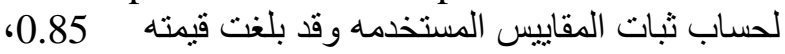

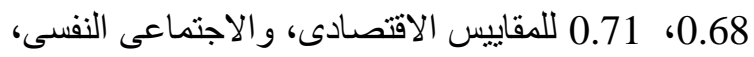

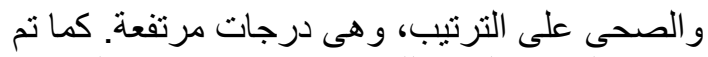

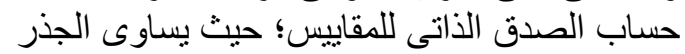

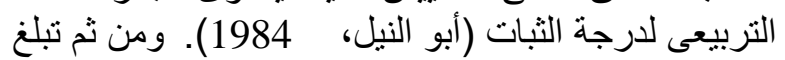

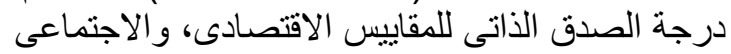

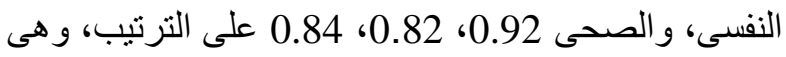

و استخدم معامل الفا كرونباخ درجات مرتفعة.

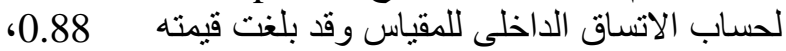

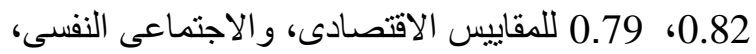

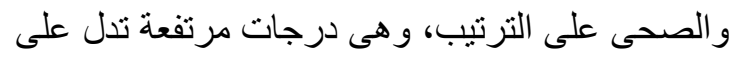
ارتفاع الاتساق الداخلى للمقاييس.

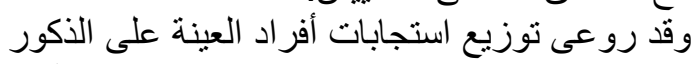

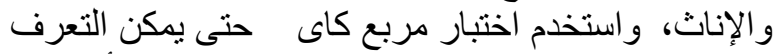

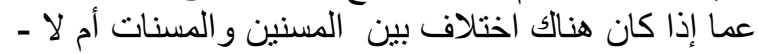
فى مستوي تلقيهم لأنو اع الدئلاف الدعم المختلفة. 1-4- الدعم الأسرى للمسن في الجن الدانب الاقتصادي وعلاقته

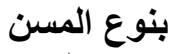

يوضح جدول (1) أن كل أفراد العينة ينوزعون على الألى الأن

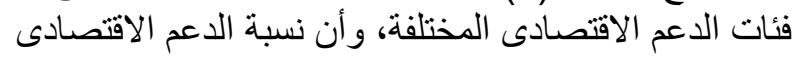

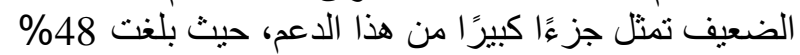

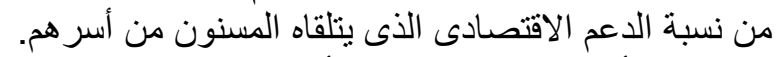

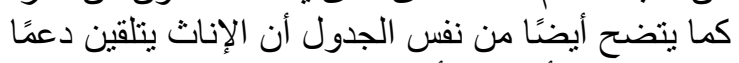

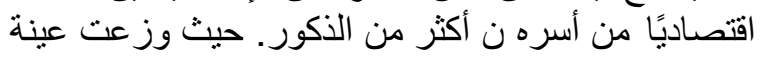

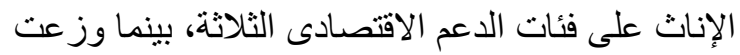

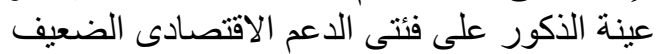

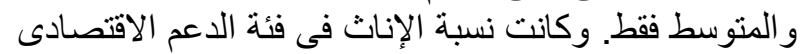

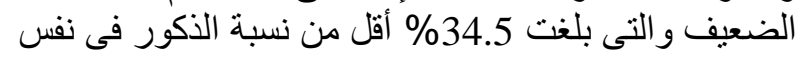

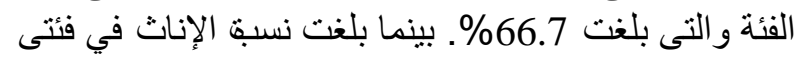

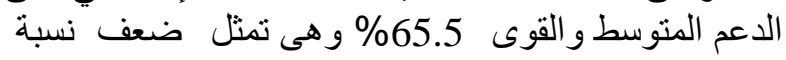

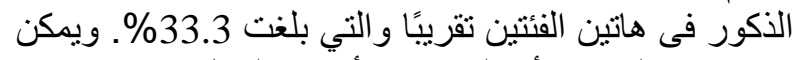

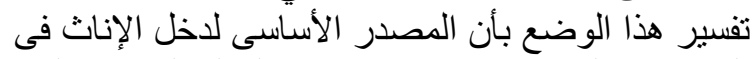

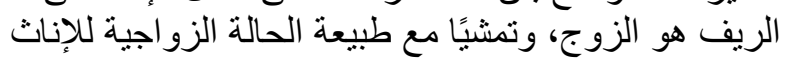

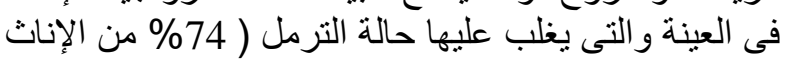

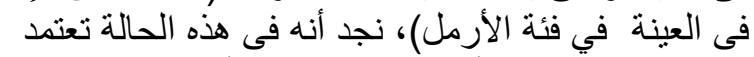

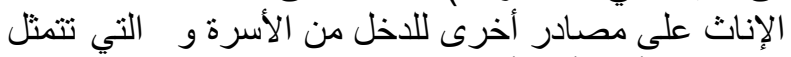

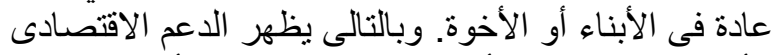

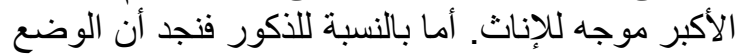

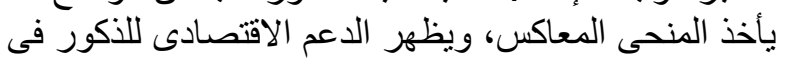

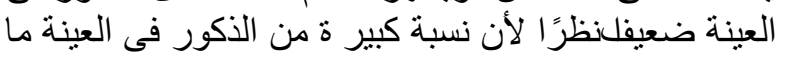

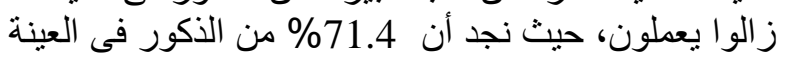

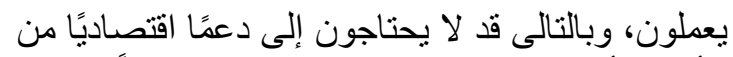

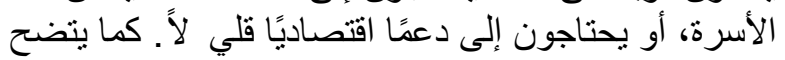

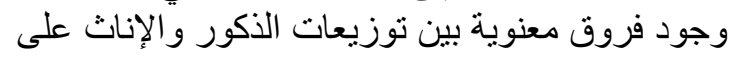

تشمل الزوج/الزوجة والأبناء فقط. 4-6-3 - الحالة التعليمية الزولة الانينة

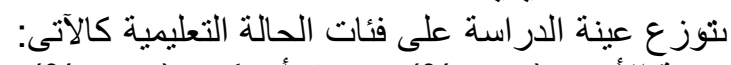

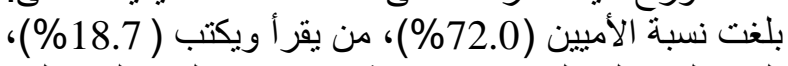

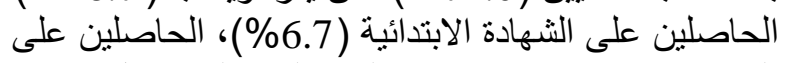

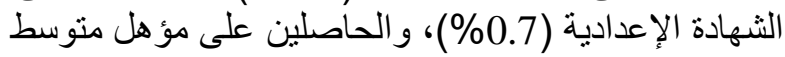

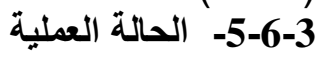

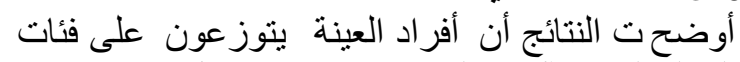

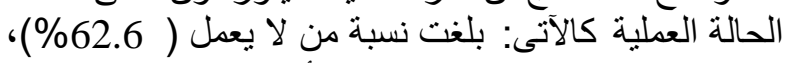

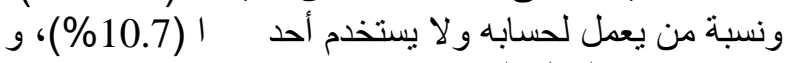

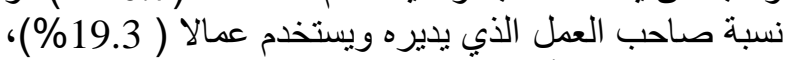

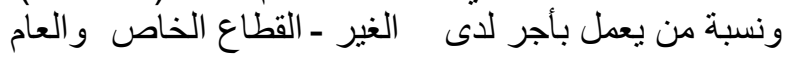

والحكومة - (7.3\%).

\section{4- نتائج الاراسة ومناقشتها}

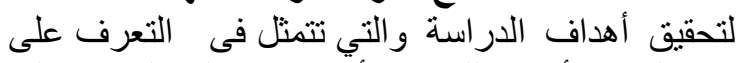

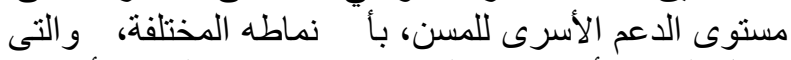

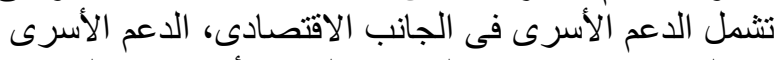

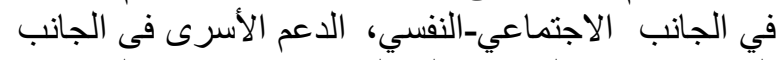

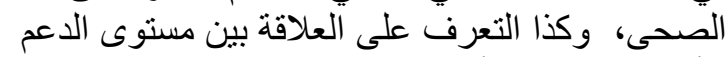

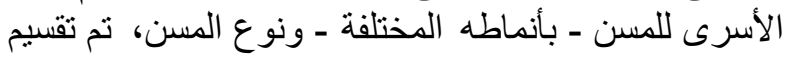

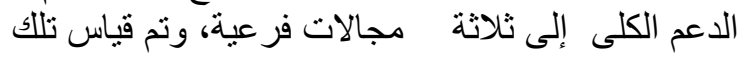

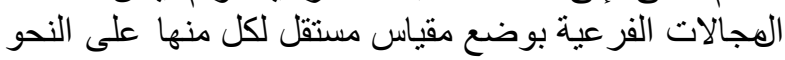

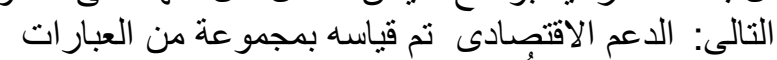

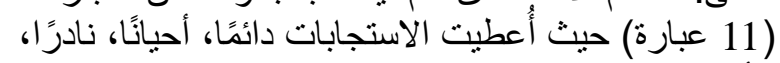

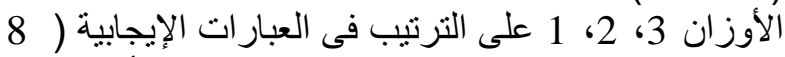

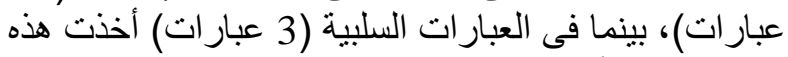

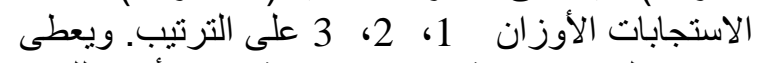
مجموع العبارات قيمة تعبر عن درجة الأن دعم الأسرة للمسن من الناحية الاقتصادية.

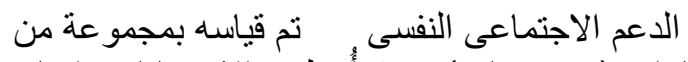

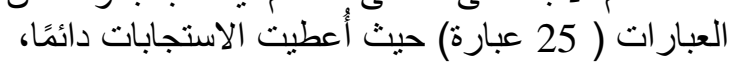

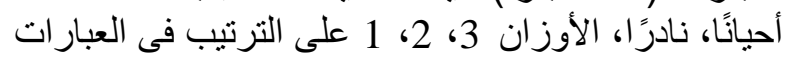

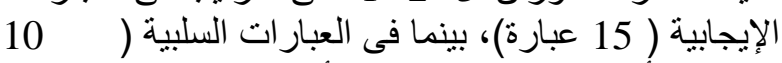

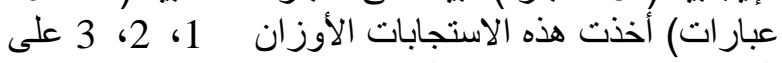

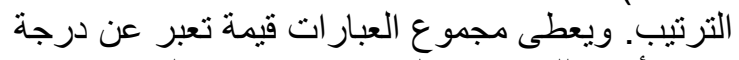
دعم الأسرة للمسن من الناحية الاجتماعية النفسية.

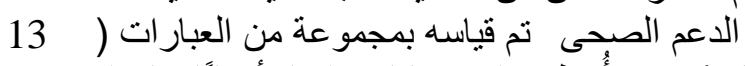

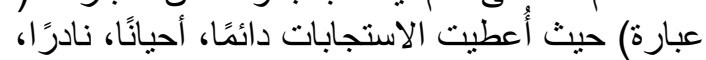

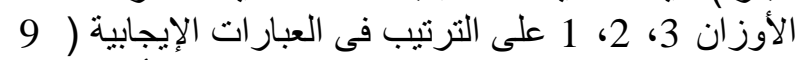

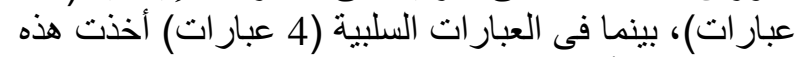

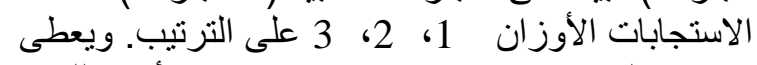

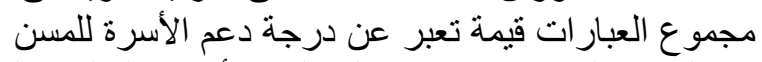

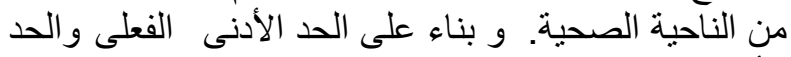

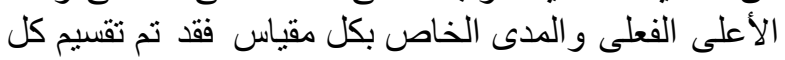

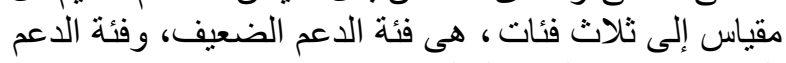

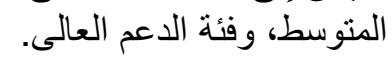

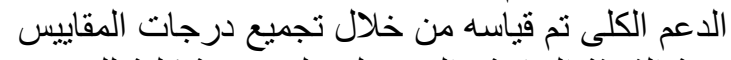

الفرعية الثلاثة السابقة و الحصول على دلى درجة كلية للدعم، 
جدول (1) : توزيع أفراد العينة طبقاً للاعم الاقتصادى المقدم من الأسرة.

\begin{tabular}{|c|c|c|c|c|c|c|}
\hline \multicolumn{2}{|c|}{ المجموع } & \multicolumn{2}{|c|}{ إناث } & \multicolumn{2}{|c|}{ ذكور } & \multirow{2}{*}{ الفئة } \\
\hline$\%$ & عدد & $\%$ & عدد & $\%$ & عدد & \\
\hline 48 & 72 & 34.5 & 30 & 66.7 & 42 & الرعم الاقتصادي الضعيف \\
\hline 38 & 57 & 41.4 & 36 & 33.3 & 21 & الدعم الاقتصادي المتوسط \\
\hline 14 & 21 & 24.1 & 21 & 0 & 0 & الاعم الاقتصادي العالي \\
\hline 100 & 150 & 100 & 87 & 100 & 63 & المجموع \\
\hline
\end{tabular}

قيمة كاى المحسوبة: 23.71، قيمة كاى الجدولية: 9.21 (عند درجات الحرية 2 بلرجة احتمال 0.01).

إضافة لما سبق فقد أوضحت الكثير من در اسات كبر

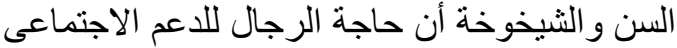

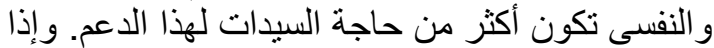
نظرنا بصفة خاصة للمجتمع الريفى، نجد أن الن المر أة فى هذا

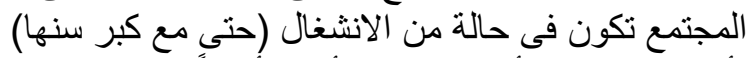

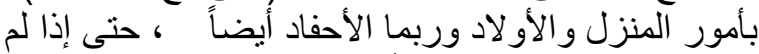

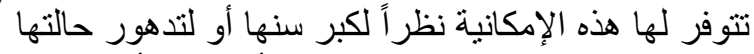

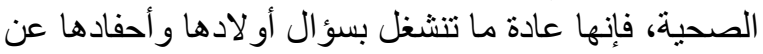

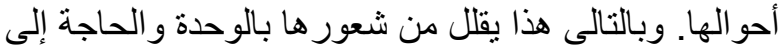

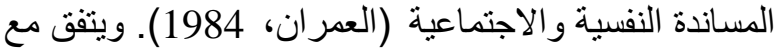

فئات الدعم المختلفة، حيث كانت قيمة كاى المحسوبة

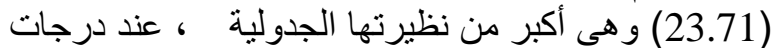

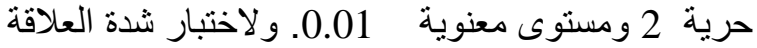

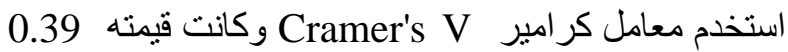
وهى تثير إلى علاقة منوسطة الثندة.

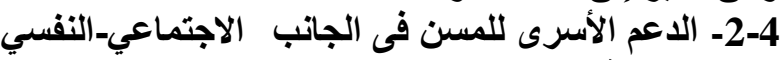

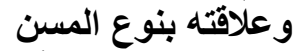

يتضح من جدول (2) أن كل أفر اد العينة يتلقون دعمًا

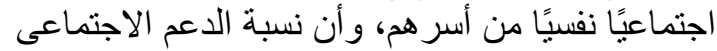

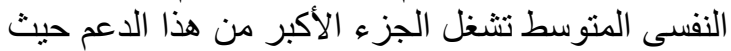
بلغت 66\% من نسبة الدعم الاجتماعى النفسى الذئى يتلقاه

جدول (2): توزيع أفراد العينة طبقاً للاعم الاجتماعى- النفسى المقدم من الأسرة.

\begin{tabular}{|c|c|c|c|c|c|c|}
\hline \multicolumn{2}{|c|}{ المجموع } & \multicolumn{2}{|c|}{ إناث } & \multicolumn{2}{|c|}{ ذكور } & \multirow[t]{2}{*}{ الفئة } \\
\hline$\%$ & عدد & $\%$ & عدد & $\%$ & عدد & \\
\hline 4 & 6 & 6.9 & 6 & 0 & 0 & الرعم الاجتماعي-التفسي الضعيف \\
\hline 66 & 99 & 83.9 & 73 & 41.3 & 26 & الرعم الاجتماعي-النفسي الهتوسط \\
\hline 30 & 45 & 9.2 & 8 & 58.7 & 37 & الرعم الاجتماعي-النفسي العالى \\
\hline 100 & 150 & 100 & 87 & 100 & 63 & المجموع \\
\hline
\end{tabular}

قيمة كاى المحسوية بعد التصحيح: 44.59، قيمة كاى الجدولية: 93 (عند درجات الحرية 2 بلرجة احتمال 0.01).

ما سبق أن 13.8\% من الإناث فى عينة الدر اسة لا يعانين

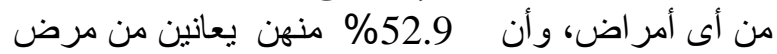

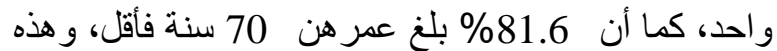

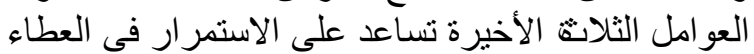

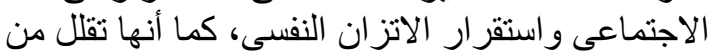

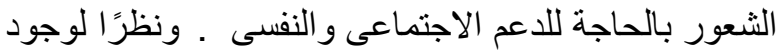

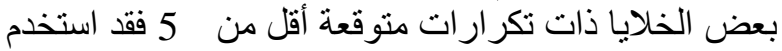

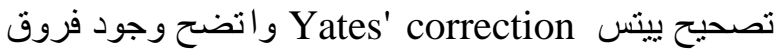
معنوية بين توزيعات الذكور و الإناث على فئئات الدعم

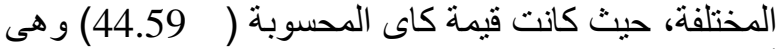
أكبر من نظيرتها الجدولية ، عند درجات حرية الاتية 2 ومستوى معنوية 0.01. و لاختبار شدة العلاقة استخدم معامل كرية كر امير وكانت قيمته 0.54 و هـى تشير إلى على الاقة قوية.

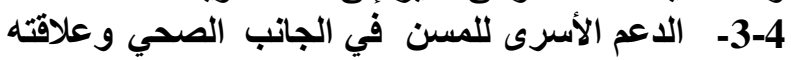
بنوع المسن
المسنون من أسر هم. كما يتضح أيضًا من نفس الجدول

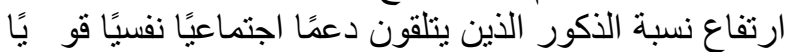
والتي بلغت 58.7\% من الذكور ، مقارنة بنسبة الإناث

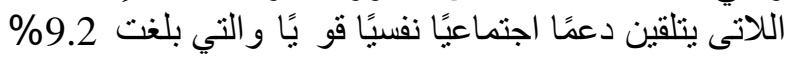

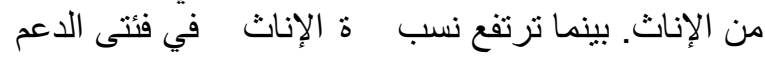

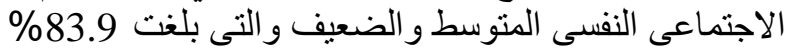

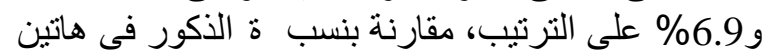

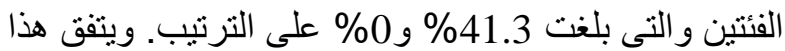

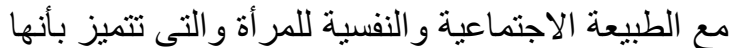

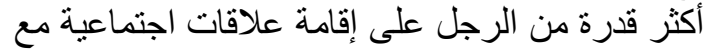

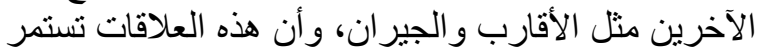

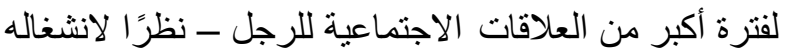

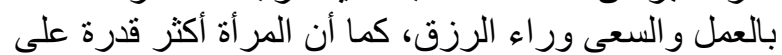

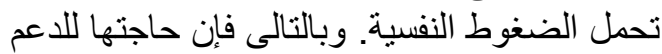

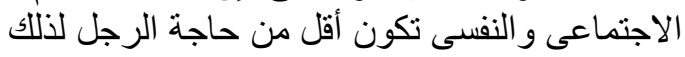

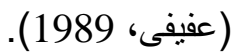


عليها من المقياس الفرعى الخاص بالاعم الاجتماعى فروفي

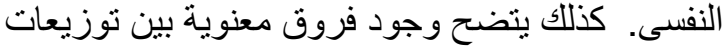

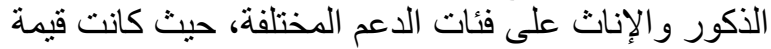
كاى المحسوبة ( 14.33) و هى أكبر من نظبيرتها الجنائ الجدولية.

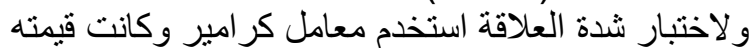
0.30 وهى تثشير إلى علاقة منوسطة الثندة. وبصفة عامة فإن النتائج السابقة توضنح الآتى:
يتضح من جدول (3) أن كل أفر اد العينة يتلقون دعمًا

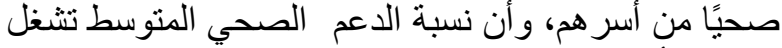

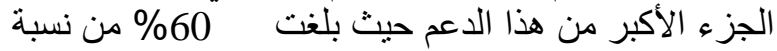

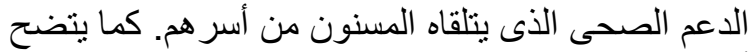

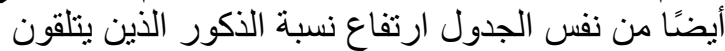

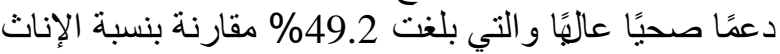

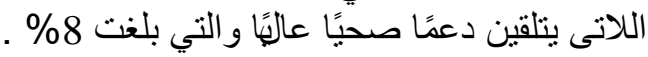

جدول (3): توزيع أفراد العينة طبقاً للاعم الصحى المقدم من الأسرة.

\begin{tabular}{|c|c|c|c|c|c|c|}
\hline \multicolumn{2}{|c|}{ المجموع } & \multicolumn{2}{|c|}{ إناث } & \multicolumn{2}{|c|}{ ذكور } & \multirow{2}{*}{ الفئة } \\
\hline$\%$ & عدد & $\%$ & عدد & $\%$ & عدد & \\
\hline 14.7 & 22 & 24.1 & 21 & 1.6 & 1 & اللعم الصحي الضعيف \\
\hline 60.0 & 90 & 67.8 & 59 & 49.2 & 31 & الرعم الصحي المتوسط \\
\hline 25.3 & 38 & 8.0 & 7 & 49.2 & 31 & الإعم الصحي العالي \\
\hline 100 & 150 & 100 & 87 & 100 & 63 & المجموع \\
\hline
\end{tabular}

- كل أفراد العينة يتوزعون على فئات الدعم المختلفة،

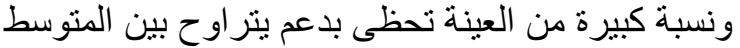

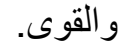

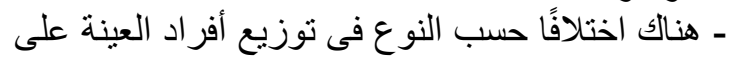

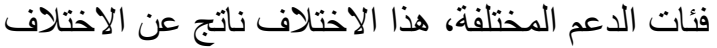
بين الذكور والإناث فى حاجتهم لأشكال الدعم المختلفة.

جدول (4): توزيع أفراد العينة طبقاً للاعم الكلى.

\begin{tabular}{|c|c|c|c|c|c|c|}
\hline \multicolumn{2}{|c|}{ المجموع } & \multicolumn{2}{|c|}{ إناث } & \multicolumn{2}{|c|}{ ذكور } & \multirow{2}{*}{ الفئة } \\
\hline$\%$ & عدد & $\%$ & عدد & $\%$ & عدد & \\
\hline 16.7 & 25 & 23 & 20 & 7.9 & 5 & دعم ضعيف \\
\hline 48.7 & 73 & 54 & 47 & 41.3 & 26 & دعم متوسط \\
\hline 34.6 & 52 & 23 & 20 & 50.8 & 32 & دعم عالى \\
\hline 100 & 150 & 100 & 87 & 100 & 63 & المجموع \\
\hline
\end{tabular}

قيمة كاى الحسوبة: 14.33، قيمة كاى الجدولية: 9.21 (عند درجات

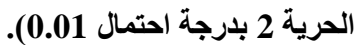

ـ الأسر الريفية في منطقة الدر اسة ماز الت تولى اهنمامًا بالمسنين وتقدم لهم الدعم و الر عاية.

$$
5
$$

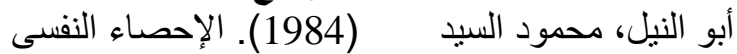

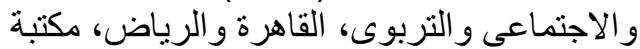

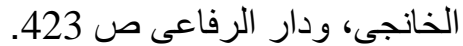

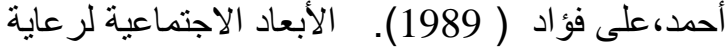

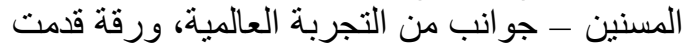
فى: رعاية المسنين فى المجتمعات المعاصرة الرئية

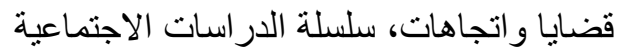

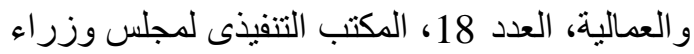
العمل و الثئون الاجتماعية بدول مجلس الكبل التعاون لدول

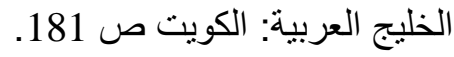

ويتفق هذا مع كثير من نتائج الدراسات السابقة التي

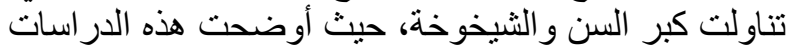

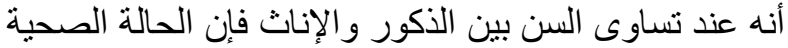

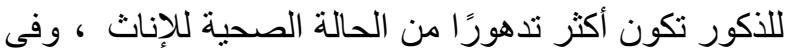

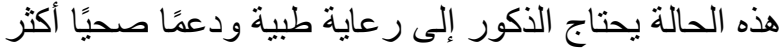

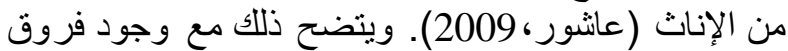

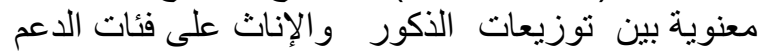

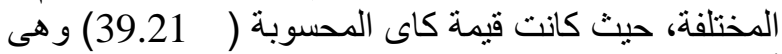

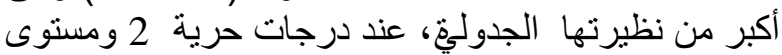

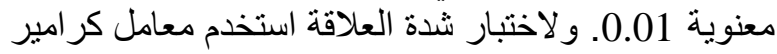

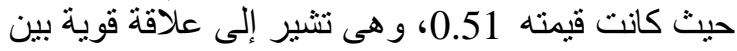
النوع ومستوي تلقي الدعم الصحي من الأسرة.

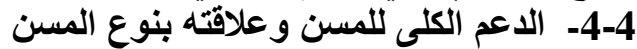

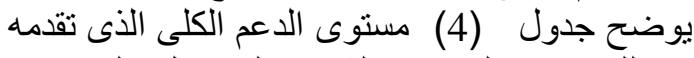

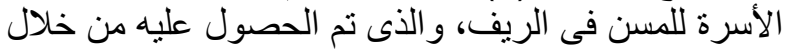

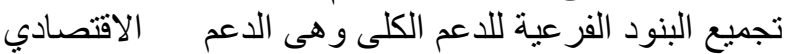

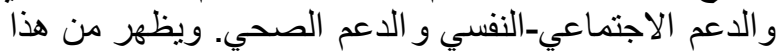

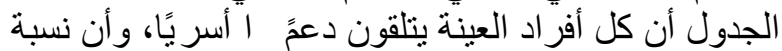

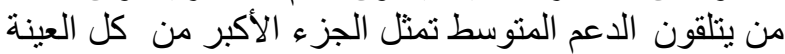

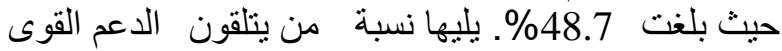

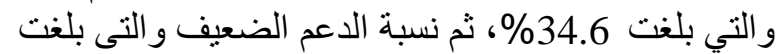

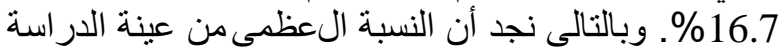

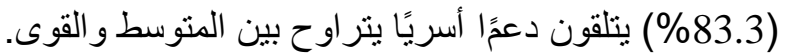

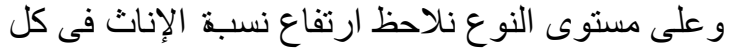

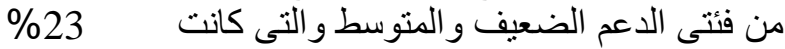
و54\% على الترنيب، عن نسبة الذكور في هاتين الفئتين

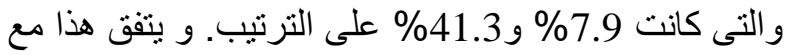

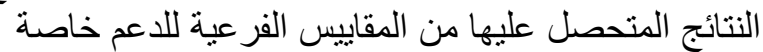

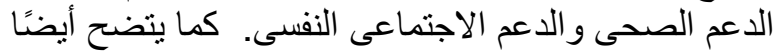

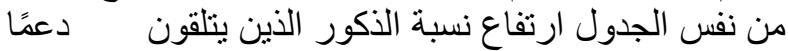

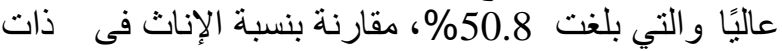
الفئة و التي بلغت 23\%. و و بتفق هذا مع النتائج المتحصل 


$$
\begin{aligned}
& \text { عاشور، عبد المنعم ( 2009). صحة المسنين كيف يمكن العان }
\end{aligned}
$$

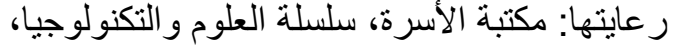

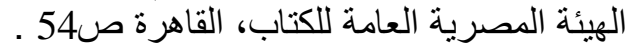

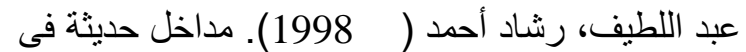

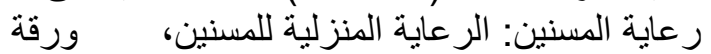

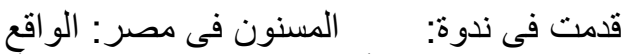

$$
\begin{aligned}
& \text { و المستقبل،13-13 أكتوبر 1998، 1998، وزارة التأمينات }
\end{aligned}
$$

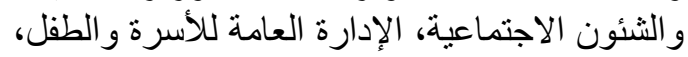

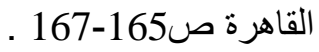

$$
\begin{aligned}
& \text { عفيفى، إلهام (1989). المر أة المسنة فى المجتمع }
\end{aligned}
$$

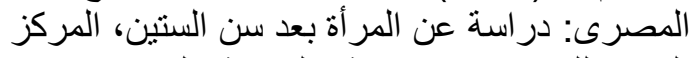

$$
\begin{aligned}
& \text { القومى للبحوث الاجتماعية و الجنائية: القاهرة ص46 العين العركي }
\end{aligned}
$$

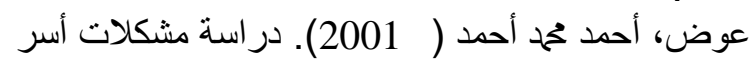

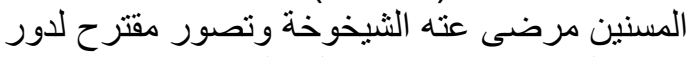

$$
\begin{aligned}
& \text { خدمة الفرد في مو اجنها، كلية الخدمة الاجتماعية، }
\end{aligned}
$$

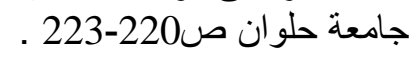

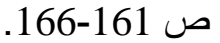

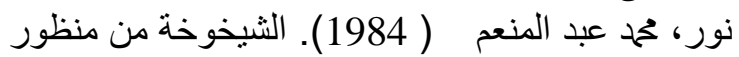

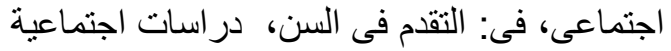

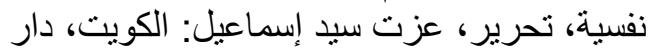

$$
\begin{aligned}
& \text { القلم، الطبعة الأولى ص صد 95-96. }
\end{aligned}
$$

\section{REFERENCES}

United Nations (1999). Population Ageing 1999, Department of Economic and Social Affairs, Population Division 19.

United Nations (2007). World Population Prospects, the 2006 Revision, Highlights, Department of Economic and Social Affairs, Population Division 63.

$$
\begin{aligned}
& \text { الصياد، جلال مصطفى ومصطفى جلال مصطفى الإحصى } \\
& \text { (1990). المعاينة الإحصائية، الرياض: داض دار المريخ }
\end{aligned}
$$

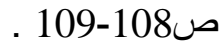

$$
\begin{aligned}
& \text { العمران، هالة أحمد (1984). التو افق النفسى للمسنين، } \\
& \text { فىى: التقدم فى السن، دراسات اجتماعية نفسية، }
\end{aligned}
$$

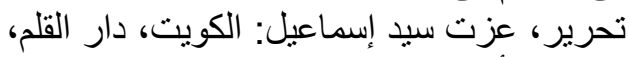

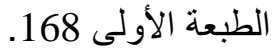

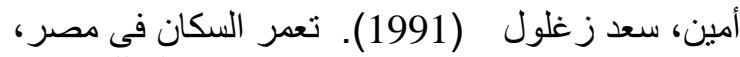

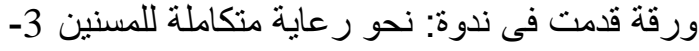

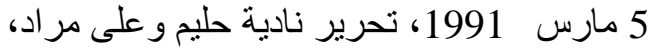

$$
\begin{aligned}
& \text { المركز القومى للبحوث الاجتماعية و الجنائية: القاهرة }
\end{aligned}
$$

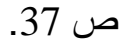

$$
\begin{aligned}
& \text { بالت، بول ( 1989). التقدم فى العمر (الثيخوخة) وكبر }
\end{aligned}
$$

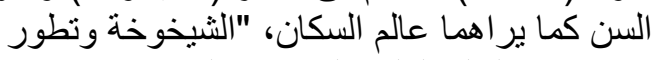

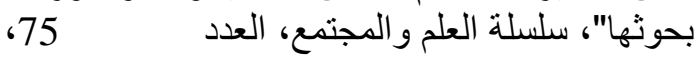

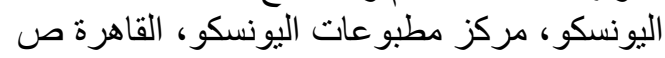

$$
\begin{aligned}
& \text {.53-43 }
\end{aligned}
$$

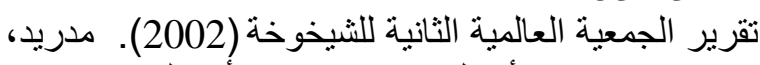

$$
\begin{aligned}
& \text { 12-8 نيسان/أبريل (2002). الامم المتحدة - } \\
& \text { نيويورك، }
\end{aligned}
$$

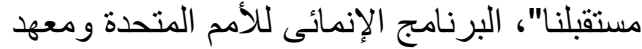

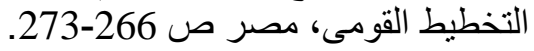

$$
\begin{aligned}
& \text { الجهاز المركزى للتعبئة العامة والإحصاء }
\end{aligned}
$$

www.msrintranet.capmas.gov.eg\plslindcslc ens_new?lang=1\&lname $=(16-9-2010)$

الجهاز المركزى للتعبئة العامة والإحصاء

http://www.msrintranet.capmas.gov.eg/owsimg2/pdf/rep12n.pdf (16-9-2010)

$$
\text { رسالة اليونسكو، يناير (1999). مركز مطبوعات }
$$

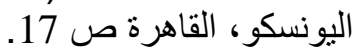

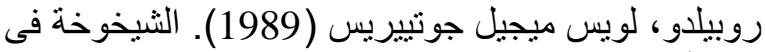

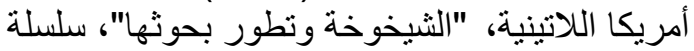

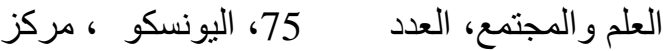
مطبو عات اليونسكو، القاهرة ص 75 65-74. 